\title{
DEVELOPING A SYSTEM OF COMPREHENSIVE CARE FOR THE SPINAL CORD INJURED PATIENT IN HOUSTON, TEXAS, U.S.A.
}

\author{
By W. H. Donovan, M.D., G. Clifton, M.D., and R. E. Carter, M.D. \\ The Institute for Rehabilitation and Research (TIRR), Houston, Texas, U.S.A.
}

\begin{abstract}
The authors agree with the principle, widely accepted, that spinal cord injured (SCI) individuals should receive all their acute, rehabilitative and follow-up care in a spinal cord injury centre. The evolution of rehabilitation medicine and services in the United States, however, has favoured the separation of acute and rehabilitation care for spinal cord injured patients, as well as other disabilities. This has resulted partly from specialisation of medical and allied health personnel, physical separation of acute and rehabilitation facilities, and reluctance of some funders of health care to see rehabilitation as a natural extension of medical care in these patients.

In Houston the proximity of a rehabilitation facility to three acute care university hospitals, representing three medical schools, provided an opportunity to improve communication among the medical personnel. These individuals have recognised the value of early rehabilitation even while the patient is acutely ill; they agreed to institute a system of care wherein the rehabilitation physician partakes in the early management in a designated area of the acute hospitals for spinal cord injured patients and works toward early transfer to the rehabilitation hospital in as ideal a condition as possible. Surgeons, who have initial primary responsibility, also visit the rehabilitation hospital, following their patient's progress at selected conferences and at the bedside. This paper describes how, a spinal cord injury service was established, how the major barriers to early transfer were confronted, and the results of the first 6 months of operation.
\end{abstract}

Key words: Spinal cord injury; Comprehensive, acute and rehabilitation care.

\section{Introduction}

SignifiCANT differences exist among developed countries of the world with regard to their respective health care systems. Recognising that care must somehow be provided for patients who cannot afford to pay, a system has nonetheless developed largely along the lines of fee-for-service within the United States of America. The evolution of treatment of the spinal cord injured patient in this country needs to be looked at against this background.

Recognition of the need for rehabilitation services across many disabilities enlarged after World War II. While the pioneer efforts of Donald Munro (I952) demonstrated the importance of preventive measures necessary to reduce the incidence of complications after spinal cord injury, it was only after World War II when he was joined by individuals such as Estin Comarr and Ernest Bors (1967) and later John Young in this country, as well as Ludwig Guttmann and others overseas, that some progress commenced. However, the concept of centres for the spinal cord injured offering comprehensive management from the onset through follow-up, as taught by Guttmann (1976), and begun by him in 1944, was never really accepted in the United States as it was in other countries such as Great Britain, Poland, Switzerland, Germany, France, Australia, New Zealand and South Africa among others. 
Rather, in the United States and Canada, the need for rehabilitation services was recognised for all disabilities and the specialty of rehabilitation medicine evolved for the purpose of serving all patients in need of rehabilitation, particularly with neuromuscular and rheumatic disorders. One of the main advantages arising from such a process was the emergence of a physician specialist who assumed the responsibility to train followers and organise the medical and allied health professionals necessary to provide rehabilitation in an environment favourable to the needs of the chronically ill. One of the major disadvantages of such a development was the creation of a process which for victims of acute trauma is unavoidably fragmentary. Patients are treated by one or one group of doctors initially until the management of the acute injury is concluded and are then transferred to a second doctor (the rehabilitation specialist) and his supporting staff for the second phase of treatment, rehabilitation.

Doubtless there are some disabilities which easily lend themselves to such an approach. The authors have seen patients with spinal cord injury treated in the latter fashion; as well as according to the method championed by Guttmann, Bedbrook and Weiss, and others, where the patient is given his acute care, his rehabilitation care and his long-term care by his physician or a group of physicians under the one roof.

Efforts are currently proceeding in this direction at a few locations within the United States and the integration of the acute care with the rehabilitation care by surgeons and rehabilitation physicians working closely together has been set as a priority by granting agencies within the federal government, including that which funds the I4 model spinal cord injury centres (1979). The ultimate goal of this effort is to ensure that the transition from acute care to rehabilitation must be applied early and specially trained staff, familiar with the complications that can arise from inexperienced management of the spinal cord injured, must be available at the location of acute treatment.

\section{Barriers}

Whilst such a structure of comprehensive care of the spinal cord injured is viewed in the United States as worthwhile by many involved in the care of such patients, significant obstacles still exist that work against implementation. One of these has been the so-called 'territoriality' of medical specialities. Spinal cord injury is a malady which requires a significant amount of expertise in numerous fields of medicine, i.e., comprehensive management crosses traditional medical specialty boundaries. Unfortunately, however, the training programmes in the United States, (as well as in many other countries) have, wittingly or not, produced physicians and surgeons who tend to evaluate a patient along the lines as to what their specialty can do for the patient's problem rather than what a patient happens to need. Thus, it is conceivable that a specialist, such as a neurosurgeon or an orthopaedic surgeon initially called to treat a patient because he happens to have a fractured spine, might be unfamiliar with those aspects of the patient's condition which involve real or potential dangers in the cardiovascular, respiratory, gastrointestinal, renal and integumentary systems, to say nothing of the psychosocial needs. Further, the assistance which such a surgeon summons from an appropriate medical specialist in one of these areas may result in a consultation by a physician who while knowing his own speciality, is unfamiliar with some of the problems unique to the spinal cord injured because he does not see a sufficient number of these patients to develop a familiarity with them. This lack of awareness of each 
other's expertise can be compounded by a lack of communication among specialists and will often result in fragmentation of responsibility and loss of continuity. This approach creates less difficulty with short-term illness but can present many problems for people with chronic illness with multi-system involvement.

Another problem in the United States is the tendency to designate hospitals as acute hospitals and rehabilitation hospitals. When such hospitals are separated geographically, the difficulty in sharing knowledge and responsibility between them is compounded even though there may be some linkage. Delays in implementation of rehabilitation philosophies and procedures readily occur while the patient becomes 'medically stable'. Likewise, follow-up by the acute treating physician after transfer to the rehabilitation hospital is made more difficult. Further, since such a strong emphasis has been placed on the avoidance of duplication of equipment and facilities, a certain amount of shuffling back and forth from one hospital to another becomes necessary whenever the facilities for diagnosing or treating a particular problem or complication are inadequate in one of the two facilities. This situation makes it virtually impossible for any single speciality or hospital to accept the responsibilities for the entire spectrum of care.

A third barrier is the seeming lack of awareness of many administrators, as well as medical and nursing leadership, of the importance of continuity of care for the severely disabled such as the spinal cord injured (as well as the head injured and victims of burn trauma). The anxiety created at the time of transferring a severely disabled person to another facility where all new medical, nursing and allied health staff must be met and learned to be trusted by the patient and his family is not generally well appreciated.

A further problem is the same apparent lack of awareness by some funders of health care such as insurance companies and state agencies, that rehabilitation of the severely injured patient is a necessary part of medical treatment. All too often providers of rehabilitation services will be told by an insurance company that a patient's policy does not cover rehabilitation or that the rehabilitation services covered are extremely limited. The fact that this can result in a premature discharge from the acute hospital with inadequate preparation of the patient and his family for coping with the altered state of physical function is not well appreciated. Unnecessary mistakes and complications can easily arise which will necessitate readmission to the acute hospital to correct them. On the other hand, state agencies charged with the duty of funding rehabilitation services for those who qualify have, in some cases, set time limits before which they will not consider rehabilitation funding. The fact that these arbitrary rules will delay the commencement of rehabilitation services for people who are truly ready for and need them also seems to have escaped these authorities.

Another socio-economic factor which impedes progress toward the goal of comprehensive management is the only too obvious fact that acute care generates greater revenues to the hospital and the treating doctors than does any long-term care programme. The major revenues generated by a hospital admission occur within the first few days, particularly if surgery is performed. Where beds can be filled by patients needing such services, it is not difficult to see that in many cases there is an unwillingness to commit beds to rehabilitation which is a longterm process.

Finally, where rehabilitation hospitals and units are in short supply, a lack of bed availability will often delay transfer of patients who might otherwise be ready. The need for more beds for the care of the spinal cord injured has been recognised by the Rehabilitation Services Administration. 
It can therefore be readily seen that some of the results of the lack of a comprehensive system of treatment of spinal cord injured patients are: $(a)$ the development of complications in the body system areas mentioned, $(b)$ the generation of anxiety in the patient and his family as to whether he will continue to receive the same degree of care, whether his chances of recovery are completely hopeless because he is leaving the acute hospital, etc.; $(c)$ the delays in the rehabilitation process being started; delays caused by holding transfer until the patient is 'stable' and delays secondary to the waiting for funding or bed availability; and finally, $(d)$ fragmentation of care.

\section{Methods}

Realising that in Houston, Texas, the authors were faced with all of the problems mentioned above, they nonetheless asked themselves how they could construct a comprehensive programme in this locale. Currently, approximately 50 per cent of the 204 spinal cord injuries occurring in the greater Houston and Galveston areas are referred immediately to three major teaching hospitals affiliated with medical schools, i.e., Hermann Hospital, Ben Taub General Hospital and John Sealy Hospital. Of all these patients only some 50 per cent are referred to the Institute for Rehabilitation and Research (TIRR) for rehabilitation; however, TIRR receives patients for rehabilitation from other hospitals in this area as well as from areas extending from well beyond it. It was recognised that in order to (a) increase the percentage of early referrals to the three area hospitals capable of managing all of the needs of trauma victims and $(b)$ increase the percentage of spinal cord injured patients referred to TIRR as soon as they could be safely transported, communication between the acute care surgeons at the acute hospitals and the rehabilitation spinal cord physicians at the rehabilitation hospital had to be improved. Steps taken were as follows: (a) communication among the neurosurgeons and the orthopedic surgeons at the three teaching hospitals and the rehabilitation hospitals at TIRR has begun; $(b)$ monthly meetings began in February I98I and deal with common goals, diagnostic and therapeutic procedures, sharing of facilities and structuring a retrieval system for the region; $(c)$ reciprocal consultation between the physicians dealing with spinal cord injuries and the surgeons dealing with acute cases at Ben Taub General Hospital was begun at once. All spinal cord injured patients admitted to Ben Taub were seen in the immediate, acute phase by the spinal cord injury physician. Recommendations were made and arrangements for transfer as early as possible were effected. Patients with cord injury but no major additional trauma were transferred as soon as possible. Patients with multiple injuries were transferred when their need for an acute intensive care setting has passed; $(d)$ follow-up by the surgeons at Ben Taub on all patients referred to TIRR has been facilitated; and $(e)$ the reciprocal consultation for the other two hospitals began slowly but is gradually improving, and similar arrangements now exist with the two other hospitals.

(a) A plan of management for the body systems other than the spine affected by the spinal cord injury was drawn up and accepted by all acute and rehabilitation participants; and, $(b)$ dialogue over the classification of fractures and the treatment of the neurological deficit was begun. Uniformity of opinion and consensus in all areas has certainly not been achieved thus far; (c) participation in the education of allied health and nursing personnel in a reciprocal fashion was also begun and finally $(d)$ both hospital administrators, as well as state agency administrators and insurance company representatives, were approached by both acute care physicians and the rehabilitation physicians together when certain policy changes were desired. 


\section{Results}

I. Agreement on a uniform plan for systems other than the spine was reached in March I98I. This addressed itself to preventing the respiratory, gastrointestinal, integumentary and renal complications among others.

2. A limited consensus over the management of closed and penetrating injuries in the cervical region was reached in April, the approach being generally conservative. Less general consensus over management of thoracic and lumbar injuries has been reached. At the present time thoracic injuries are generally managed conservatively and dorso-lumbar injuries are managed operatively.

3. The visiting consultation programme has been established and information is being shared by reciprocal consultations, and during conferences. All patients referred to the three Hospitals are seen by rehabilitation doctors and the transition has become quite smooth for the physicians, the nursing and allied health staff as well as for the patient and his family. Progress is being made in this direction at the other two hospitals. Acceptance of it in principle has been achieved and is nearing implementation.

4. General consensus was reached over the areas in the region from which the three hospitals should receive their spinal cord injured patients. It was agreed that all would promote referral in the agreed upon direction, even though current physician referral patterns may create exceptions.

5. A seminar for outlying areas of the catchment region is being organised.

6. Early referrals to the rehabilitation hospital has been facilitated by restructuring the priorities of the rehabilitation hospital admission policy. Patients who are referred from the three teaching hospitals are given priority and are admitted as soon as the patient is medically and economically cleared. The incidence of complications (particularly pneumonia), has been reduced allowing earlier transfer, while the ability to handle patients who still have medical problems within the rehabilitation hospital has improved. Further, it was recognised that in many instances the rehabilitation hospital was in a better position to cope with some of the medical problems such as urological, skin and respiratory management than the referring hospitals.

\section{SUMMARY}

This paper describes the conditions which have mitigated against the evolution of spinal cord injury care along the lines championed by Sir Ludwig Guttmann wherein comprehensive care is given in a single institution known as a spiral cord centre. Efforts made to approach such an ideal within the framework of the American Health Care System and the limitation imposed by it in Houston, Texas, U.S.A. are presented.

\section{RÉSUMÉ}

Cette étude décrit les conditions qui ont attenué l'évolution des oisns a apporter aux blessures à la moelle épinierè selon les principes soutenus par Sir Ludwig, selon lesquels des soins complets seraient administrés dans une seulle institution désignée comme centre pour moelle épinierè. On a présenté les efforts pour approcher d'un tel idéal selon les règlements du American Health Care System et les limitations qui sont imposées par ce systeme à Houston, Texas, USA. 


\section{ZUSAMMENFASSUNG}

Die Abhandlung beschreibt die Umstande die die Entwicklung der Behandlungprinzipe von Rückenmarkverletzungen erleichtert haben im Sinne den Sir Ludwig Gutmann verteidigte und zwar die Bahndlung in einzelner spezialisierten Anstalt in dem sogenannten Rueckenmarkzentrum. Die Anstrengungen dieses ideal in Houston, Texas, U.S.A. zu erreichen werden beschrieben und diskutiert mit Bezug auf die Organization des amerikanischen Gesundheitssystems und seine Begrenzungen.

\section{REFERENCES}

Bors, E. (1967). The Spinal Cord Injury Center of the Veterans Administration Hospital, Long Beach, California, U.S.A., Facts and Thought. Paraplegia, 5, I26.

GuttmanN, Sir L. (1976). Spinal Cord Injuries-Comprehensive Management and Research, 2nd ed., pp. 26-40, Blackwell Scientific Publications, Oxford.

MunRo, D. (1952). Treatment of injuries to the nervous system. W. B. Saunders, Philadelphia.

NoticEs (I979). Federal Register, 44, 98, 294I2-294I4. 